\title{
Fernando Nadra ante los gobiernos de Héctor José Cámpora y Juan Domingo Perón
}

Fernando Nadra during Héctor José Cámpora and Juan Domingo Perón governments

Lucia Arturi*

Resumen: En este trabajo se buscará analizar los posicionamientos del dirigente comunista Fernando Nadra ante el tercer gobierno de Perón y de su antecesor, Héctor José Cámpora. Tomando como principal fuente sus notas editoriales en el semanario oficial del Partido Comunista de la Argentina, Nuestra Palabra, se indagará además en su conceptualización de la violencia en los años 1973 y 1974.

Palabras clave: Comunismo, Perón, Cámpora, violencia

\begin{abstract}
This paper will study the communist leader Fernando Nadra's political stances with respect to Perón's third government and Héctor José Cámpora's previous presidency. Furthermore, on the basis of Nadra's editorial notes published in the oficial argentinian communist weekly, Nuestra Palabra, this work will focus in his conceptualization of violence in the years 1973 and 1974.
\end{abstract}

Key words: Communism, Perón, Cámpora, violence

Recibido: 19 junio 2018 Aceptado: 5 agosto 2018

\section{Introducción}

Si bien a primera vista el período analizado (1973 - 1974) puede suscitar extrañeza por tratarse de un lapso temporal reducido, cabe mencionar lo siguiente: es cierto. Fueron pocos meses. Pero lo fueron de una vorágine y vértigo poco antes vistas. La presidencia de Héctor José Cámpora, recordada como la "primavera camporista", duró lo que cualquier primavera. Acto seguido, Juan Domingo Perón retornó tras 17 años de exilio, asumió y al poco tiempo murió dejando atónita a toda la población. En su lugar, gobernaría su viuda, María Estela Martínez de Perón sin demasiada experiencia política y sin demasiada legitimidad. Poco a poco, por decretos y leyes aprobadas en el Parlamento, se autorizaría la intervención de las Fuerzas Armadas.

\footnotetext{
${ }^{*}$ Argentina. Licenciada en Historia por la Universidad Torcuato Di Tella y doctoranda en Historia por la Universidad Nacional de San Martín. Correo electrónico: luchia.arturi@gmail.com
} 
Contemporáneamente, el tablero político, sumido en un "espiral de violencia"1, era cohabitado por varias agrupaciones que legitimaban el uso de las armas. La organización político-militar más relevante era Montoneros que se había convertido en un movimiento jerárquico y numeroso, aunque también operaba en el terreno el guevarista Ejército Revolucionario del Pueblo (ERP) y distintas agrupaciones de la derecha peronista (entre ellas, la más conocida, la Alianza Argentina Anticomunista o "Triple A").

Al examinar la literatura escrita sobre este período podemos observar que se han privilegiado temáticas como las organizaciones armadas y la construcción e implementación de políticas estatales. Esto responde a que la "violencia política" (tanto de las organizaciones guerrilleras como la represión estatal) muchas veces ha tomado el carácter de noción explicativa de la dictadura cívico-militar (1976-1983) y del trienio peronista $(1973-1976)^{2}$. Suelen primar los trabajos que giran en torno a "la militancia setentista", ya sea desde un lugar condenatorio como reivindicativo ${ }^{3}$ y se ha dejado de lado el análisis del sistema de partidos argentino. Poca es la atención que ha tenido el Partido Comunista (de ahora en más, PC) ya que sólo ha sido abordado de manera tangencial y fragmentaria en textos cuyo objeto de estudio es más general ${ }^{4}$.

Además, se carece de estudios biográficos completos sobre la dirigencia política de principios de los setenta (salvo por biografías sobre Perón, el líder montonero Mario Firmenich, Cámpora y López Rega) ${ }^{5}$. Es decir, no se ha tenido en cuenta a líderes que, como el comunista Fernando Nadra, podrían complejizar el análisis de la situación política a principios de los setenta. Por lo tanto, en pos de reconstruir su trayectoria política, en este trabajo nos concentraremos en sus posicionamientos, tácticas y estrategias ${ }^{6}$ en 1973 y 1974. Sin embargo, ¿por qué podría suscitar interés el análisis de esta figura? Fernando Nadra constituye una figura polémica y cuestionada dentro de Partido Comunista por sus afirmaciones durante este período y durante la dictadura cívico-militar (1976 - 1983). La fuerte autocrítica reinante en el XVI Congreso del Partido Comunista, realizado en 1986, puntualizó la responsabilidad de la cúpula partidaria ${ }^{7}$ de la que no quedó exento Nadra por ser la voz pública del PC en los setenta.

\footnotetext{
${ }^{1}$ James, Daniel (dir.), Nueva Historia Argentina, vol. 9, “Violencia, proscripción y autoritarismo: 1955-1976” Buenos Aires, Sudamericana, 2007, p. 320.

2 Cernadas, Jorge, Tarcus, Horacio y Pittaluga, Roberto, "Para una historia de la izquierda en Argentina" en El Rodaballo, año III, $\mathrm{n}^{\circ} 6-7$, otoño-invierno 1997.

3 Nos referimos a las lecturas que han realizado Pilar Calveiro para analizar a Montoneros y Claudia Hilb para estudiar al PRT-ERP. Ambas autoras han puntualizando la responsabilidad de las organizaciones armadas mientras que los trabajos de Eduardo Anguita y Martín Caparrós, Ernesto Jauretche y Marta Diana reivindican las acciones militantes.

${ }^{4}$ Excepto por los análisis de Daniel Campione que estudia de manera acotada la trayectoria política del Partido Comunista, Isidoro Gilbert que se centra en la dinámica, líderes y posicionamientos de la Federación Juvenil Comunista, Cristina Tortti que da cuenta de los debates y rupturas que comienzan a instalarse en la "izquierda tradicional" (el Partido Comunista y Partido Socialista) a la luz de la Revolución Cubana, la China maoísta y movimientos africanos de liberación nacional a mediados de los cincuenta, Natalia Casola que indaga de manera profunda el rol del PC durante la dictadura, la bibliografía sobre el partido suele ser reducida.

5 Entre los que se pueden hallar numerosos ensayos periodísticos como Marcelo Larraquy que indaga en la figura de López Rega, y en cómo estableció su maquinaria represiva, Joseph Page en donde se concentra sobre la vida política del jefe de estado, etc.

6 Diferenciamos "táctica" de "estrategia", definiendo a la segunda como un objetivo de largo alcance que requiere la realización de un conjunto de pasos a los denominamos "tácticas”. Más información en Lenin, Vladimir Ilich, El izquierdismo, enfermedad infantil en el comunismo. Buenos Aires, Editorial Cártago, 1969

7 Para más información, Casola, Natalia. El PC argentino y la dictadura militar. Militancia, estrategia política y represión estatal. Buenos Aires, Imago Mundi, 2015.
} 
Ahora bien, Nadra (1916 - 1995) fue nombrado en 1973 director de Nuestra Palabra, órgano central del Partido Comunista. Este semanario (de ahora en más, $N P$ ) tuvo un tiraje que llegó a los 50.000 ejemplares de acuerdo a cifras del propio órgano ${ }^{8}$. Este abogado tucumano, miembro del Comité Central del PC, no sólo fue el portavoz de las tácticas comunistas dentro del partido sino también fuera de él. En el período analizado, como mencionamos, fue la figura pública del partido y su representante. Entró en contacto con Perón y con María Estela Martínez de Perón, además de ser un miembro activo en las sucesivas reuniones multipartidarias que se realizaron en el marco del "Pacto político" (es decir, el acercamiento con otros partidos políticos planeado por el viejo caudillo) ${ }^{9}$.

Para ese entonces, Nadra ya contaba con una amplia trayectoria política. Había sido presidente de la Federación Universitaria de Córdoba y Secretario General de la Federación Universitaria Argentina, además de presidente de la Federación de Estudiantes Secundarios, en su Tucumán natal. Cuando decidió ingresar al Partido Comunista en 1939, abandonó la profesión de abogado para dedicarse al partido como un "revolucionario profesional"10. Para principios de los setenta, formaba parte de la avejentada dirigencia del PC 11 .

Este partido no sólo contaba con una significativa estructura partidaria (desde el partido se declaraba que habían 150.000 afiliados en todo el país ${ }^{12}$ ) sino que también, en estos años, tuvo una enérgica participación en la arena política. No obstante, desde los años sesenta, el PC debió reacomodarse ante el surgimiento de la "nueva izquierda"13. El advenimiento de alternativas a la Unión Soviética, como la China maoísta y la Revolución Cubana pusieron en cuestión el lugar de faro de la revolución que se había arrogado la Unión Soviética. De ahora en más, el Partido Comunista y Partido Socialista serían llamados por diferentes sectores, la "Izquierda tradicional".

Cabe mencionar que el objetivo del PC no era la revolución socialista en Argentina, sino la Revolución democrático burguesa ¿por qué? Porque consideraba que en las orillas del Plata el capitalismo no se había desarrollado y primaba, por el contario, una estructura "semi-feudal" en la que lideraba la elite terrateniente. Por ello, se creía fundamental la reforma agraria y se deseaba una "revolución por etapas", en la que primero debería ocurrir, como se mencionó, una revolución "democrática, antiimperialista y agraria" (y su progresivo avance industrial y burgués) que tendría al socialismo como etapa posterior y superior. Quien no respetara este

\footnotetext{
8 En forma de semanario empezó a producirse el 8 de marzo de 1950, como continuación de la revista Orientación, (también editada por el Partido Comunista) y fue dirigido, en sus comienzos, por Rodolfo Ghioldi, por su hermano, Orestes y en momentos de legalidad, por Héctor P. Agosti.

${ }^{9}$ Sin ánimos de sustituir la riqueza de las experiencias del Partido Comunista por el discurso de Fernando Nadra que no deja de ser uno entre varios puntos de vista dentro del PC, cabe señalar que su lugar dentro del esquema organizacional del partido era relevante, como se mencionó, al conformar el Comité Central.

10 Nadra, Fernando. La Religión de los ateos. Reflexiones sobre el estalinismo en el Partido Comunista Argentino. Buenos Aires, Puntosur editores, 1989, p. 14.

11 Según Natalia Casola la burocratización del partido (es decir, la distancia de los cuadros dirigentes del resto de los miembros del partido) se entreveía en dirigentes que como Nadra se habían eternizado en sus puestos.

12 Vale aclarar que la categoría "afiliado" remite a un sujeto que está inscripto al partido pero que no necesariamente milita de manera activa en la organización. Por lo tanto, la cifra contemplada podría no ser exacta al estar al servicio de fines propagandísticos. No obstante, Natalia Casola plantea que el PC se constituyó en los setenta como una alternativa atractiva para parte de la población que simpatizaba con la izquierda pero que desconfiaba del accionar guerrillero.

13 Tortti, María Cristina. "Izquierda y 'nueva izquierda' en la Argentina. El caso del Partido Comunista.", Sociohistórica, $\mathrm{N}^{\circ} 6,1999$.
} 
etapismo, es decir, quien buscara una revolución socialista inmediata sería titulado como "ultraizquierdista". Pero veremos esta cuestión más adelante...

\section{Cámpora al gobierno}

El 11 de marzo de 1973, la ciudadanía volvió a votar después de diez años sin poder hacerlo. Una febril ilusión se había apoderado de la juventud, principal protagonista del momento, ante la posibilidad de entronizar al peronismo en el gobierno bajo la sonrisa protectora de Héctor José Cámpora. Vale recordar que "el Tío" había sido elegido por Perón para participar de las elecciones como salida a la "cláusula de residencia" (un artilugio legal dictaminado por el militar Alejandro Agustín Lanusse, que prohibía la candidatura de aquellos que no estuvieran en el país).

Al finalizar los comicios, casi seis millones de votos fueron los que coronaron al "tío" Cámpora como jefe de gobierno. El FREJULI ${ }^{14}$ obtuvo el 49,5 por ciento de los votos frente a la Unión Cívica Radical, cuyo candidato, Ricardo Balbín decidió con un 21,29%, renunciar a la segunda vuelta.

En este escenario político, ¿dónde se ubicaba el Partido Comunista? El PC había conformado, en 1971, un frente de "centro izquierda", la Alianza Popular Revolucionaria (integrado por el Partido Intransigente, Revolucionario Cristiano, Udelpa, etc) y había presentado sus candidatos para las elecciones del 11 de marzo de 1973. En estas elecciones, si bien sus candidatos (Oscar Alende del Partido Intransigente y Horacio Sueldo del Partido Revolucionario Cristiano) quedaron en cuarto lugar, con 885.201 votos (es decir, el 7,43\% de los votos), el partido obtuvo dos diputados (Juan Carlos Comínguez y Jesús Mira). Fue la primera vez que representantes comunistas ocuparon bancas en el Congreso.

Ahora bien, las elecciones del 11 de marzo de 1973 significaron para el Partido Comunista, por un lado, su retorno a la legalidad y por otro, el fin del tormento que había representado la dictadura de la Revolución Argentina15.

¿Cuál fue la táctica del PC de la Argentina en este momento? Tanto durante el gobierno de Cámpora como durante la presidencia de Perón, el PC adoptó una fórmula de balance de suma y resta: "apoyar lo positivo y criticar lo negativo"16. De esta manera, mostrándose moderado, el PC decidió preservar su estructura. Siguiendo este esquema, Fernando Nadra vio con buenos ojos la amnistía que otorgó Cámpora a los presos políticos de la cárcel de Villa Devoto ${ }^{17}$.

En segundo lugar, se puede observar la aprobación del dirigente comunista a la política internacional. Nadra resaltó que en el acto de asunción de Cámpora asistieron el presidente chileno Salvador Allende, y su par cubano, Osvaldo Dorticós. Es más, juzgó como "positivo" el

\footnotetext{
14 El Frente Justicialista de Liberación reunía al Movimiento de Integración y Desarrollo, algunos democristianos, socialistas y conservadores populares.

15 La Revolución Argentina fue una dictadura militar, inaugurada por Juan Carlos Onganía en 1966 al derrocar, mediante un golpe de estado, al presidente radical Arturo Illia.

16 Esta fórmula que consiste en apoyar al gobierno cuando éste estuviese en sintonía con los objetivos comunistas ya se había implementado luego de derrota de la Unión Democrática (que el PC había integrado) ante Juan Domingo Perón en las elecciones de 1946. Es decir, se trata de un proceder tradicional dentro del partido. 17 Allí se encontraban militantes de Montoneros, del Ejército Revolucionario del Pueblo (ERP), entre otros, que habían sido apresados durante la dictadura.
} 
impulso que dio el ministro de Economía José Ber Gelbard a las relaciones comerciales con Cuba y otros países socialistas. "Nunca se había hecho tanto en tan poco tiempo" mencionaría Fernando Nadra cuando renuncie Héctor Cámpora; figura que para él era prometedora.

Durante la breve presidencia de Cámpora (y también, durante la presidencia de Perón), Nadra insistió en que se cumpliesen las Pautas Programáticas "para el Gobierno Justicialista de la Reconstrucción Nacional”. Estas pautas constituían el programa electoral de Cámpora, donde prometía independencia económica, lucha contra el imperialismo y la oligarquía, además de la ya clásica "justicia social". En cierta medida, Fernando Nadra vio que se asemejaban estas propuestas a los objetivos comunistas, lo que lo llevó a tomar la victoria de Cámpora como una victoria del partido. Este triunfo electoral significaba para Nadra no sólo la aceptación y legitimación civil del programa camporista sino también del programa comunista. Por ende, asumió que la revolución democrática y antiimperialista era lo que deseaba el pueblo. Fernando Nadra describiría al movimiento justicialista como "revolucionario de izquierda, aunque no comunista"18. Y más adelante, cuando se reuniría con Juan Domingo Perón en la Casa Rosada (vale aclarar, la primera vez que se realizó una reunión entre miembros del Partido Comunista y el viejo líder) diría a la prensa: “(...) entre comunistas y peronistas en la base como en los programas y objetivos revolucionarios, no hay una muralla. Por el contrario, hay acuerdos y coincidencias que hay que impulsar y profundizar" 19.

Lo único que Fernando Nadra criticó como "negativo" en varias notas editoriales fue el Pacto Social concertado entre el ministro de economía, José Ber Gelbard (presuntamente comunista), la CGT (liderada por José Ignacio Rucci) y la CGE (Central General Económica, que agrupaba a los empresarios). Este acuerdo, que definió la política económica tanto de Héctor Cámpora como de Perón, respondía al antiguo postulado peronista de la "alianza de clases". Aunque de difícil aplicación, postergaba la recuperación salarial y congelaba los precios para combatir la inflación. Desde el Comité Central del PC, el dirigente Fernando Nadra lo caracterizaba de la siguiente manera: "es un acuerdo firmado por la burguesía sin la más mínima participación de la clase obrera en su elaboración y su firma. (...) Fue urdido por representantes patronales y firmado por los jerarcas sindicales a espaldas de los trabajadores y en detrimento de éstos." 20 Además, resaltaba el perfil del secretario general de la CGT, José Ignacio Rucci como "el jerarca más odiado por la clase obrera" 21, integrante de una "traidora y corrompida burocracia sindical.“22

\section{La cuestión de la violencia}

Las cúpulas sindicales, por ese entonces, se encontraban enfrentadas a la juventud peronista por el control del movimiento; y Juan Domingo Perón, después de 17 años de habitar en el exilio y de incentivar estratégicamente esta tensión, volvía a Argentina como mediador. Sin embargo, su esperado retorno a Ezeiza no terminaría de la mejor manera. Sectores de la derecha peronista dispararon a la multitud reunida en el aeropuerto. Luego de cometida esta masacre, Perón comenzaría a cambiar su retórica pro guerrillera por un acercamiento a los

\footnotetext{
18 Nuestra Palabra, Año I, N7, 08/08/1973, p.16.

${ }_{19}$ Nuestra Palabra, Año I, N 14, 26/09/1973, p.8.

20 Nuestra Palabra, Año I, N 30, 23/01/1974, p.3.

21 Nuestra Palabra, Año I, N³, 12/07/1973, p.3.

22 Nuestra Palabra, Año I, N 37, 13/03/1974, p.3.
} 
"viejos peronistas", dando así inicio a su "giro a la derecha". Nuestra Palabra dedicó a estos sucesos varias páginas y acusó a "elementos reaccionarios y proimperialistas" de haber provocado la masacre. Sin embargo, la prensa tradicional señaló como victimarios a los "bolches". A esta última acusación la podemos entender si tenemos en cuenta que, conjuntamente con una deslegitimación general de la violencia durante el período democrático, se comenzó a vislumbrar la circulación de un discurso en contra del "enemigo interno" (o "subversivo"), ${ }^{23}$ infiltrado, con ideologías foráneas o comunistas. En un principio, se entremezcló de manera confusa, la concepción de la "subversión" con el comunismo, aspecto que perjudicará al PC.

No obstante ¿cómo pensaba la violencia el dirigente Fernando Nadra? Éste percibió la violencia a través de una mirada dicotómica y a la estructura comunista como en medio de la balacera ${ }^{24}$. Existía, para Nadra, un "terrorismo de derecha" y un "terrorismo de izquierda" o "ultraizquierda".

Por un lado, según Nadra, la derecha penetraba en todos los campos de la actividad argentina. No sólo efectuaba "actos terroristas", sino que también promovía el desabastecimiento, el contrabando y el mercado negro para desarrollar un clima de inestabilidad y descontento generalizado. Además, de acuerdo al director, la derecha imperialista yanqui y sus agentes locales, buscaban frenar "el proceso de liberación", ocupando el gobierno desde adentro o produciendo un golpe de estado, similar al de Augusto Pinochet.

En principio, antes de Ezeiza, se atribuye el "terrorismo de derecha" 25 a grupos de comando ("brigadas de choque" o grupos parapoliciales) y matones de los jerarcas sindicales ("gorilas"). Sin embargo, de a poco, Nadra puntualizará como responsable a la "Triple A" (liderada por el ministro de Bienestar Social, José López Rega) y nombrará una y otra vez como referentes del terrorismo de derecha a los jefes de la policía federal, Alberto Villar y Luis Margaride. El director de $N P$ verá una "ola de terrorismo de derecha" y llamará a unir a "todas las fuerzas patrióticas y antiimperialistas - civiles y militares-, sin discriminaciones ni prejuicios" 26 .

Todas las semanas en Nuestra Palabra se reportaron amenazas, asesinatos, secuestros, voladuras de locales partidarios y de centros estudiantiles. Aproximadamente, entre la asunción de Cámpora y mediados de 1974, se registraron en Nuestra Palabra, 6 asesinatos de afiliados comunistas, 28 presos, 5 atentados contra locales del PC o FJC, 2 allanamientos, 5 atentados contra particulares, 3 secuestros, y 2 amenazas. La violencia y la muerte se transformaron en una banalidad cotidiana. Por este motivo, se realizaron movilizaciones, denuncias y pedidos de investigación por parte del PC y la Liga Argentina de los Derechos del

\footnotetext{
${ }^{23}$ Marina Franco aclara que la idea de "enemigo interno" ya estaba instalada en las Fuerzas Armadas en los sesenta, en publicaciones ligadas a las misiones francesas del Ejército argentino. Se podría agregar la influencia de la doctrina norteamericana con sus teorías de la contrainsurgencia (o "guerra contrarrevolucionaria" en el caso francés), y la Escuela de las Américas, en el Canal de Panamá donde, durante la Guerra Fría, varias tropas fueron a entrenar. 24 Daniel Campione define al PC como una "izquierda no armada" ya que a pesar de contar con armas y con un entrenamiento militar, no incluían acciones militares en su práctica política. Para más información: Campione, Daniel. "La izquierda no armada en los años '70 en Argentina” [en línea] Dirección URL: www.lahaine.org [Consulta: 5 de Marzo de 2018]

25 A veces se lo llama "subversión contrarrevolucionaria" (Nuestra Palabra, Año I, № 9, 22/08/1973, p.8)

${ }^{26}$ Nuestra Palabra, Año I, N²3, 28/11/1973, p.3.
} 
Hombre ${ }^{27}$. Se demandaba, principalmente al Congreso, que realice informes y que se conforme una comisión parlamentaria.

Por otro lado, Nadra pensaba que la "ultraizquierda" era dueña de una ideología pequeño burguesa e infantil por su impaciencia revolucionaria (según el director, no eran conscientes de que "no existían las condiciones objetivas para la revolución"). Además, creía que su terrorismo individual, "suicida", sin el apoyo de las masas obreras, desencadenaba represión contra revolucionaria. Entraban bajo esta denominación "ultraizquierdista" el trotskismo, el maoísmo, y particularmente el Ejército Revolucionario del Pueblo. ${ }^{28}$

Marina Franco señala que este repudio a la violencia de "tenor bipolar" era recurrente en los discursos de la época aunque variaba el énfasis según los actores ${ }^{29}$. Sin embargo, es llamativo cómo se ubica Nadra respecto de Montoneros y las Fuerzas Armadas Revolucionarias (FAR). Nadra comenta que "importantes sectores de las FAR y los Montoneros" 30 se encuentran constituidos por fuerzas democráticas, patrióticas y antimperialistas. Esta postura se hace más clara si se tiene en cuenta que divisiones comunistas como la Juventud Comunista (o FJC), en sintonía con la idea de "trabajo unitario", realizaban actividades en conjunto con Montoneros y la Juventud Peronista, en congresos y reuniones de las Juventudes Políticas Argentinas. Convenía, por otro lado, al PC acercarse a esta fracción del peronismo ya que conformaba, para este tiempo, un movimiento de masas con gran legitimidad.

Nadra insistió más en el terrorismo de derecha que en el terrorismo de izquierda ${ }^{31}$. Puede que, por buscar vínculos con la izquierda peronista, su táctica era más cuidadosa con aquellas organizaciones que se encontraban más a su izquierda. Es probable que no criticara tanto a la "ultraizquierda" por no ser específicamente "el enemigo", sino que servía al enemigo.

No obstante, fuera del "terrorismo de derecha" y el "terrorismo de izquierda", cabe preguntarse cómo pensó el accionar del Estado y la responsabilidad de Perón durante su presidencia. Tanto durante el gobierno de Cámpora como durante la presidencia de Perón, Nadra sostendrá la "Teoría del Cerco"32. Es decir, disoció a Perón de todo hecho de violencia. El "cerco" era conformado por la derecha dentro del gobierno, y de una manera más extensa y abarcativa, por el imperialismo yanqui a través del Operativo "Cono Sur" o "Plan Arcángel".

27 Véase para más información sobre la Liga Argentina de los Derechos del Hombre, la ponencia de Natalia Casola "Apuntes para una historia política de los derechos humanos en Argentina: El caso del Partido Comunista y la Liga de los Derechos del Hombre durante la última dictadura militar". Dirección URL:

http://conti.derhuman.jus.gov.ar/2011/10/mesa_1/casola_mesa_1.pdf [Consulta: 2 de marzo de 2018]

28 Es interesante, a su vez, indagar en cómo se conceptualizaba el “timing” de los terrorismos. Según Marina Franco, el PC como muchas organizaciones, indicaban que el terrorismo de derecha había sido producto del terrorismo de izquierda. En la ultraizquierda recaería, según los comunistas, la culpa de iniciar la escalada de violencia que, en su momento, parecía desenfrenada. Sin embargo, la presión de la derecha existió desde siempre, afirmaba Nadra. Sólo que, por momentos, se repliega "para reagrupar fuerzas, preparar sus organizaciones paramilitares y parapoliciales contrarrevolucionarias". A fines de 1975, Nadra invierte el timing de los terrorismos, postulando que la derecha "(...) su misión además de matar, es la de sembrar terror (...) Incitar a los revolucionarios a hacerles el juego del terrorismo". En suma, en ciertos momentos, Nadra conceptualiza la "subversión" como consecuencia de la pobreza. Por este motivo, privilegiaba, para combatirla o prevenirla, las políticas económico-sociales más que la represión. ${ }^{29}$ Franco, Marina. "Notas para una historia de la violencia en la Argentina: una mirada desde los discursos del período 1973- 1976” Nuevo mundo. Mundos nuevos, Paris: año 2008, vol. 2008, p. 1-11.

30 Nuestra Palabra, Año I, N4, 18/07/1973, p.3

31 Esto mismo puede observarse en Nadra, Fernando, Reflexiones sobre el terrorismo, Buenos Aires, Aporte Ediciones, 1976.

32 La juventud peronista, al ser cada vez más excluida del campo político por Perón, también argumentaba en base a esta "Teoría del cerco". Fundamentaban que existía un cerco internacional (es decir, imperialista) y nacional (mejor dicho, su entorno, y particularmente, Lopez Rega). 
Es más, en el XIV Congreso del Partido Comunista en el que participó Nadra, se decidió votar por la fórmula de Juan Domingo Perón y María Estela Martínez de Perón el 23 de septiembre de 1973 ¿por qué? ¿Por qué apoyarlo a Perón si durante su primer y segundo gobierno (1946 - 1955) el PC lo había defenestrado? En una entrevista televisiva a Fernando Nadra, un periodista insistió en este punto:

Periodista: (...) ¿Ustedes no van a repetir el error del '46?

Nadra: Primero, no es error del '46, fue un gran acierto. Tenía una fundamentación diferente. Hoy han cambiado los tiempos. Hay una nueva situación (...) en la que hemos contribuido grandemente los comunistas. Cuando una masa peronista se dice que es de izquierda o avanza hacia la izquierda (...). A todo eso no es ajeno la labor de nuestro partido.

Periodista: ¿Ese es el cambio más importante que usted nota entre el '46 y el '73?

Nadra: En el orden interno sí, la revolurización (sic) de las masas y en el orden externo, los cambios en América Latina y en el mundo (...)

Periodista: ¿O esta actitud del comunismo es consecuencia de la autocrítica?

Nadra: No, de ninguna manera. Aquí no hay autocrítica. Aquí lo que hay es un largo y paciente trabajo de los comunistas $(. . .)^{33}$

Aquí se entrelazan en Nadra una mirada dogmática y la incapacidad de realizar un análisis autocrítico. En síntesis, para el dirigente, la situación había cambiado: las masas giraban a la izquierda y Perón había dejado de ser nazi o fascista (como se lo había llamado en las elecciones de 1946) para transformarse en un líder que buscaba una "auténtica" revolución ${ }^{34}$. Curiosamente Nadra esbozó como "razones para votar la fórmula Perón-Perón" la crisis económica (inflación y altas tasas de desempleo) "heredada de la dictadura" y "la conspiración de la derecha". Aunque, más que razones, estos pronunciamientos parecen exigencias... Claramente, detrás de estos enunciados, existía un atisbo pragmático. A diferencia de sus dos primeros gobiernos, Perón se mostraba conciliador y esto podría constituir una invaluable oportunidad para el PC. Se trataba de algo inédito, el viejo líder, abierto al diálogo, escucharía sus demandas (¿Cuántas puertas se abrirían si contaban con Perón como aliado?). Además, como este "león herbívoro" 35 era ambiguo retóricamente, permitía al PC y a dirigentes como Nadra, moldear sus palabras a medida (aspecto que no dejó de explotar el PC, ya que, a fin de cuentas, -pensaba Nadra-, sus enunciados eran cercanos). De esta manera, el dirigente tucumano sumó su apoyo a la fórmula peronista: "No estamos interesados en el fracaso del

\footnotetext{
33 Entrevista a Fernando Nadra, realizada por Sergio Villaroel. Capital Federal, 22 de agosto de 1973. Archivo Difilm, Buenos Aires, Argentina.

34 Es más, según Casola, en 1972 se intentó tender lazos con el peronismo, pero fracasaron las gestiones para conformar una fórmula electoral. Por lo tanto, el PC formó la APR.

35 Silvia Sigal y Eliseo Verón, Perón o muerte. Los fundamentos discursivos del fenómeno peronista, Buenos Aires:

Eudeba, 2010, página 144.
} 
gobierno. Si este gobierno impulsa decididamente el programa de la liberación nacional y social encontrará a los comunistas en la primera línea de combate" 36.

\section{Perón al poder}

Perón se consagró por tercera vez como presidente y el Partido Comunista continuó con su táctica de "apoyar lo positivo y criticar lo negativo". En sus notas editoriales, Fernando Nadra se opuso a varias leyes represivas del Poder Ejecutivo. Entre las más criticadas, la reforma de la ley de Asociaciones Profesionales (que, según Nadra, buscaba "impedir las asambleas para que los obreros no puedan opinar; elecciones con lista única y completa, para que nadie más pueda estar representado; para perpetuar la jerarquía actual; (e) impedir huelgas e intervenir en las organizaciones"); la Ley de Prescindibilidad utilizada más tarde durante la dictadura cívico-militar (1976 - 1983) constituía para el dirigente comunista "un arma de discriminación política"37 que llevaría al despido de obreros y empleados estatales; la Ley de Arbitraje obligatorio que "desconoce el arbitraje como derecho obrero y otorga esa facultad al Ministro de Trabajo (Otero)"38; además de la ley de radicación de capitales que según Nadra, "significa una concesión a los monopolios extranjeros". Se trataban, por un lado, de leyes orientadas al mundo laboral que Perón buscaba restringir, y por otro lado, de un proyecto de ley que tenía a la inversión extranjera como principal objetivo para mejorar la situación económica. Finalizado el año 1973, el director de Nuestra Palabra percibía que la inestabilidad económica y política persistía desde la dictadura de la Revolución Argentina. Sin embargo, no responsabilizaba puntualmente al jefe de estado.

Aun así, Nadra se llevó una desagradable sorpresa cuando el mismo Perón estableció expresamente que los planes de su gobierno se asentaban en el Pacto Social y que aquellos que querían violarlo servían "otros intereses que no son de la Nación y de su pueblo". El director de $N P$, preocupado, agregó que "A nadie escapa que esta artillería es descargada no contra los representantes de la gran burguesía y de los monopolios, a quienes elogió como patriotas (...) sino contra los obreros" 39 .

Peor aún fue el llamado de atención después del atentado del ERP a una guarnición militar en la localidad de Azul el 20 de enero de 1974. Perón tomó este hecho para impulsar la reforma al Código Penal y así, castigar duramente las "actividades subversivas". Si bien el Comité Ejecutivo del PC emitió un comunicado reprochando este ataque guerrillero, rechazó de plano la reforma al Código Penal ya que, en palabras de Fernando Nadra, creaba nuevas figuras delictivas, "tales como: incitación a la violencia, o los llamados delitos contra la seguridad común" 40 . La vaguedad de esta reforma, según el dirigente comunista, constituía un peligro para las libertades públicas y "significa(ba) resucitar, agravándola, la legislación represiva que existía en la época de la dictadura de los monopolios". A este proyecto se opuso también gran parte de la Tendencia Revolucionaria, como los jóvenes diputados del FREJULI que renunciaron a sus bancas. Dentro de la interna peronista donde competían la juventud peronista y los grandes sindicatos, Fernando Nadra tomó partido por los jóvenes que perseguían la "patria

\footnotetext{
36 Nuestra Palabra, Año I, № 9, 22/08/1973, página 8.

37 Nuestra Palabra, Año I, N²9, 16/01/1974, p.3.

38 Nuestra Palabra, Año I, N²8, 09/01/1974, p.5.

39 Nuestra Palabra, Año I, N³0, 23/01/1974, p.3.

40 Nuestra Palabra, Año I, Nº 29, 16/01/1974, p .1
} 
socialista". Sabiendo esto, podemos imaginarnos cuál fue la posición del dirigente frente a una fecha tan decisiva para el movimiento peronista como el primero de mayo de 1974 . Al acto por el día del trabajador, el PC no asistió, pese a la invitación del gobierno nacional. Los comunistas realizaron su propio acto en Plaza Italia en el que demandaron democracia sindical y ocho horas de trabajo. Si bien la relación entre la juventud peronista y Perón venía resquebrajándose, este día marcó el final de su vínculo. Perón, desde el balcón de la Casa Rosada, acusó de "estúpidos e imberbes" a los jóvenes peronistas que se retiraron dejando casi vacía la Plaza de Mayo. Días después, Perón, disolvería la rama juvenil del Partido Justicialista.

La repercusión de este suceso en Nuestra Palabra fue importante. En primera plana, el 8 de mayo, se publicó la nota editorial de Nadra cuyo título dejaba entrever la problemática: "El Partido Comunista y lo de Plaza de Mayo". En él, se mencionaba lo siguiente:

En cuanto al Presidente Perón, aunque se pueda hablar de un rapto emocional o de una improvisación provocada por la acción de los montoneros, el hecho real es que, quizá sin proponérselo, borró buena parte de lo que había expuesto en la Asamblea Legislativa. (...) Debemos decirle al Presidente que en nada ayuda al proceso revolucionario y, por el contrario, alienta a los verdaderos conspiradores de derecha, el duro ataque lanzado contra la Juventud Peronista. Nadie puede ignorar -y nosotros tampoco- que la juventud peronista y sus aguerridos montoneros constituyen el sector más combativo y más avanzado del peronismo, los más fieles a las pautas programáticas de liberación, y los que han dado, desde sus filas, la mayor cuota de sangre y de sacrificio en la lucha contra la dictadura. (...) Le reiteramos al Sr Presidente: el discurso y la actitud de Plaza de Mayo constituyen un error evidente, que deberá corregirse de inmediato ${ }_{2}$ para bien de la juventud peronista, para bien del país y para el buen éxito de la lucha contra el golpe de Estado y el neocolonialismo (el destacado es propio)

El panorama varía unos días después. El 12 de junio, según Nadra, Perón no se equivoca, sino que brinda el discurso más emblemático para el partido comunista. Desde ese momento en adelante, sus palabras y esta fecha serán retomadas en la dialéctica de Nadra. El director de Nuestra Palabra mencionará en un artículo que el presidente denunció al imperialismo, a la oligarquía y a sus agentes reaccionarios por llevar a cabo un plan de perturbación política y económica, destinado a crear el descontento popular. Sin embargo, faltaría poco para que este discurso y la figura de Perón se conviertan en recuerdo. El 1ero de julio de 1974, fallecería el general.

A pesar de que, haciendo un balance, hubo más políticas que se le criticaron, Fernando Nadra continuó apoyando a Perón. Ignoró su "giro a la derecha" y adjudicó la responsabilidad por las medidas autoritarias y represivas a los agentes de derecha dentro y fuera del gobierno (a través de la "teoría del cerco"). Nadra probablemente depositó más expectativas en este gobierno que en los otros dos anteriores por la cercanía táctica y las posibilidades de acción que se abrieron con Perón ${ }^{41}$.

\section{Conclusiones}

41 Una recopilación de las notas editoriales que describen los encuentros de Perón y Nadra también pueden hallarse en Nadra, Fernando. Conversaciones con Perón, Buenos Aires, Anteo, 1986. 
Sin ánimo de exhaustividad, hasta aquí hemos realizado un recorrido tentativo por los posicionamientos, tácticas y estrategias del dirigente Fernando Nadra durante los gobiernos de Cámpora y Perón. De manera preliminar, a través de sus notas editoriales, hemos detectado que el dirigente actuó con pragmatismo. En este acotado pero vertiginoso tiempo, las tácticas de Nadra se fueron perfilando de acuerdo al escenario cambiante al que tuvo que hacer frente. Si bien recayó en ciertas contradicciones, la estrategia de una revolución democrática y antiimperialista se mantuvo intacta.

Si bien este trabajo persigue el objetivo de trazar la trayectoria política de este dirigente, notamos que aún es necesario indagar en su accionar en momentos previos y posteriores (para comprender, por ejemplo, su retirada del Partido a fines de los ochenta y también su apoyo al menemismo).

Claro que queda pendiente no sólo un estudio profundo del Comité Central comunista (incluso de dirigentes históricos como Victorio Codovilla quien había fallecido en 1970, el secretario general, Athos Fava, los hermanos Rodolfo y Orestes Ghioldi, entre otros) sino también un acercamiento analítico a la militancia en este período. Además, cabría contrastar las afirmaciones de Nadra con publicaciones y escritos de otros líderes comunistas del interior de país. Es decir, notar las repercusiones, paralelismos o contradicciones de las cúpulas comunistas a nivel federal.

\section{BIBLIOGRAFÍA:}

Libros:

- Campione, Daniel. "El Partido Comunista de la Argentina. Apuntes sobre su trayectoria”, en M. Modonesi, E. Concheiro Bórquez y H.Crespo (cords.), El comunismo: otras miradas desde América Latina, México: UNAM, 2007

- Casola, Natalia, EI PC argentino y la dictadura militar. Militancia, estrategia política y represión estatal. Buenos Aires: Imago Mundi, 2015.

- De Riz, Liliana. Retorno y derrumbe, el último gobierno peronista. Buenos Aires: Hyspamerica, 1987.

- $\quad$ De Riz, Liliana. La Política en suspenso, 1966- 1976. Buenos Aires: Paidós, 2000.

- $\quad$ Di Tella, Guido. Perón-Perón, 1973-1976. Buenos Aires: Hyspamerica, 1986.

- Franco, Marina. Un enemigo para la nación. Orden interno, violencia y "subversión", 1973 1976, Buenos Aires: Fondo de Cultura Económica, 2012.

- James, Daniel (dir.), Nueva Historia Argentina, vol. 9, "Violencia, proscripción y autoritarismo: 1955-1976" Sudamericana: Buenos Aires, 2007.

- $\quad$ Nadra, Fernando. Conversaciones con Perón, Buenos Aires, Anteo, 1986.

- Nadra, Fernando. La Religión de los ateos. Reflexiones sobre el estalinismo en el Partido Comunista Argentino. Buenos Aires, Puntosur editores, 1989

- Sigal, Silvia y Verón, Eliseo. Perón o muerte: los fundamentos discursivos del fenómeno peronista. Buenos Aires: Eudeba, 2010.

- Svampa, Maristella. "El populismo imposible y sus actores" en Daniel James (dir.), Nueva Historia Argentina, 1955-1976, vol. IX, Buenos Aires: Sudamericana, 2003

- Torre, Juan Carlos. El gigante invertebrado: los sindicatos en el gobierno, Argentina 1973 1976. Buenos Aires: Siglo Veintiuno Editores, 2004. 
Artículos en revistas:

- Casola, Natalia. “ ¡Soldados de la patria no apunten contra el pueblo! El Partido Comunista Argentino en vísperas del golpe militar (1975)”, Conflicto Social, Año 3, № 3, Junio 2010.

- Casola, Natalia. “iLos comunistas no somos subversivos! El PC y la dictadura militar argentina (1976-1983)", Archivos de historia del movimiento obrero y la izquierda, Año I, N 2, Marzo de 2013.

- Cernadas, Jorge, Tarcus, Horacio y Pittaluga, Roberto, "Para una historia de la izquierda en Argentina” en El Rodaballo, año III, n 6 - 7, otoño-invierno 1997.

- Franco, Marina. "Notas para una historia de la violencia en la Argentina: una mirada desde los discursos del período 1973- 1976", Nuevo mundo. Mundos nuevos, Paris: año 2008, vol. 2008, p. 1-11.

- Franco, Marina. "La 'seguridad nacional' como política estatal en la Argentina de los años '70", Antíteses vol. 2, No. 4, (Julio-diciembre, 2009), p. 865. [en línea] Dirección URL: http://www.uel.br/revistas/uel/index.php/antiteses [Consulta: 2 de Diciembre de 2017]

- Tortti, María Cristina. "Izquierda y 'nueva izquierda' en la Argentina. El caso del Partido Comunista.", Sociohistórica, № 6, 1999

- Tortti, María Cristina. "La nueva izquierda a principios de los '60: socialistas y comunistas en la revista Ché”, Estudios sociales, №22·23, 2002.

Ponencias:

- Campione, Daniel, "Hacia la convergencia cívico-militar. Partido Comunista y "Frente Democrático”, 1955 - 1976.” En Congreso “II Jornadas de Historia de las Izquierdas”, 11, 12, 13 de Diciembre de 2002, Facultad de Cs Exactas (UBA)

- Campione, Daniel. "La izquierda no armada en los años '70 en Argentina” [en línea] Dirección URL: www.lahaine.org [Consulta: 5 de Marzo de 2018]

- Casola, Natalia. "Apuntes para una historia política de los derechos humanos en Argentina: El caso del Partido Comunista y la Liga de los Derechos del Hombre durante la última dictadura militar". Dirección URL:

http://conti.derhuman.jus.gov.ar/2011/10/mesa_1/casola_mesa_1.pdf [Consulta: 2 de marzo de 2018]

Fuentes primarias:

- Nuestra Palabra, año I, número 1, 26/06/1973 - Nuestra Palabra, Año II, número 53, 09/07/1974.

- Entrevista a Fernando Nadra, realizada por Sergio Villarroel. Capital Federal, 22 de agosto de 1973. Archivo Difilm, Buenos Aires, Argentina. 